\title{
FEM analysis of piston for aircraft two stroke diesel engine
}

\author{
Pawet Magryta ${ }^{1, *}$, and Michat Gęca ${ }^{1}$ \\ ${ }^{1}$ Faculty of Mechanical Engineering, Department of Thermodynamics, Fluid Mechanics and Aviation Propulsion Systems, Lublin \\ University of Technology, ul. Nadbystrzycka 36, 20-618 Lublin, Poland
}

\begin{abstract}
The paper presents an analysis of piston thermal loads in an opposed piston engine. The purpose of the work was to check the achieved thermal values of different piston models. Two types of pistons were analysed. The first piston was made entirely of aluminium. The second one was a split piston, made of steel and aluminium. Simulation studies were performed using Abaqus software. Boundary conditions were taken from previously made simulations conducted in AVL Fire software. The wall temperature of the piston was mapped from CFD combustion model. The results of the analyses were illustrated by the distribution of temperature fields on a piston surface. The distribution of temperature fields on the piston surface shows that maximum temperatures are located on sharp edges of a piston bowl, values of maximum temperatures are 402 and $512{ }^{\circ} \mathrm{C}$ for aluminium and composed piston respectively.
\end{abstract}

\section{Introduction}

Piston is a highly thermo-mechanically loaded part. Firstly, it is heated during a combustion process, by forced convection with a combustion flux and then cooled by forced convection with engine oil and conduction with piston rings and a cylinder block. These heat exchanges generate transient loading cycles in a component, which, coupled with severe, external, mechanical loads, induce transient thermal-mechanical loadings. The repetition of these transients thermomechanical cycling is responsible for the piston cracking [1,2].

In the opposed piston engine, in each cylinder there are two pistons moved by two crankshafts (figure 1). Typically, these are two-stroke engines with uniflow scavenging. One of the pistons opens inlet ports and second exhausts ports. The designed OPOS engine does not have cylinder heads, as in classic designs of combustion engines, in which a fuel injector is mounted. Its location in the head allows a fuel stream to be injected and burned in the direction of a cylinder's axis. The design of a combustion chamber in the piston of the planned OPOS engine differs significantly from the design of the engine with head. The combustion chamber is composed of two identical pistons coming together form an elongated ellipsoidal combustion volume, where the injectors are located at the end of the long axis. The injectors are positioned perpendicular to the cylinder axis. Fuel is injected in this direction as well. All the heat released during combustion is absorbed by the walls of the combustion chamber formed by two pistons cooled from the inside by an oil spray.

Pistons for combustion engines generally are produced from cast or forged, high-temperature resistant aluminium silicon alloys. The majority of pistons are produced by gravity die casting. Forged pistons from eutectic and hypereutectic alloys exhibit higher strength and are used in high performance engines where the pistons are subject to even high stresses. Forged pistons have a finer microstructure than cast pistons with the same alloy composition. The production process results in greater strength in the lower temperature range. A further advantage is the possibility to produce lower wall thicknesses and hence reducing the piston weight. Also, aluminium metal matrix composite materials are used in special cases. Pistons with $\mathrm{Al}_{2} \mathrm{O}_{3}$ fibre reinforced bottoms are produced by squeeze casting and used mainly in direct injection diesel engines. The main advantage, apart from a general improvement of mechanical properties, is an improvement in thermal fatigue behaviour [3, 4].

Aluminium alloys for high temperature applications decrease strength when exposed to high temperature. Hardenable aluminium alloys starts to diminish mechanical strength markedly just at 150 to $200^{\circ} \mathrm{C}$ and that the mechanical properties of cast aluminium alloys are strongly influenced by the metallurgical and microstructural properties. Various hardenable cast aluminium alloys have been studied and compared regarding their applicability as diesel engine cylinder heads [5].

For designing aircraft and automotive engines parts, prototypes are usually used on test bench for applying load in complex but close to real conditions [6]. These test benches are usually not very flexible in terms of loading conditions, difficult to set up and expensive. Moreover, it is not easy to make a link between the laboratory piston test and the real load observed in real

${ }^{*}$ Corresponding author: p.magryta@pollub.pl 
engine. Authors analysed thermal fatigue of automotive Diesel piston. Test piston was internally cooled by permanent water flow while its bowl sensitive to thermomechanical fatigue was subjected to cyclic induction heating [7].

The use of simulation studies to optimise structures is now common. Until recently, mainly due to the lack of access to computers with high computational power, it was not possible to perform strength and fatigue analysis of complex structures. Analytical methods used at the time were efficient but based on simple mathematical relationships that were appropriate for the static loads on the structure. Today, the ability to access a wide range of simulation software (strength, fatigue, etc.) reduces design time and optimises new structures.

In the paper [8] authors focus on employing a combined experimental and numerical approach to understand and demonstrate injection pattern effects on improving piston thermal management in an opposite piston OP2S engine. They use a modified version of the commercially available one, to perform in-cylinder simulations of the OP2S combustion system. The model was correlated by measurements. Heat transfer to the combustion chamber consists of two pistons and is strongly influenced by the power cylinder design, including the injection spray pattern, piston bowl shape and port configuration.

Based on the project POIR.01.02.00-00-0002/15 financed by the Polish National Centre for Research and Development, a new construction of opposed piston engine was proposed (figure 2). The engine requires application of mechanical compressor. Crankshafts are connected with each other via a gear transmission. The engine subjected to research is characterised by a power of $100 \mathrm{~kW}$, with a capacity of about 1.61 , with a diesel cycle. The engine is equipped with a direct diesel injection system.

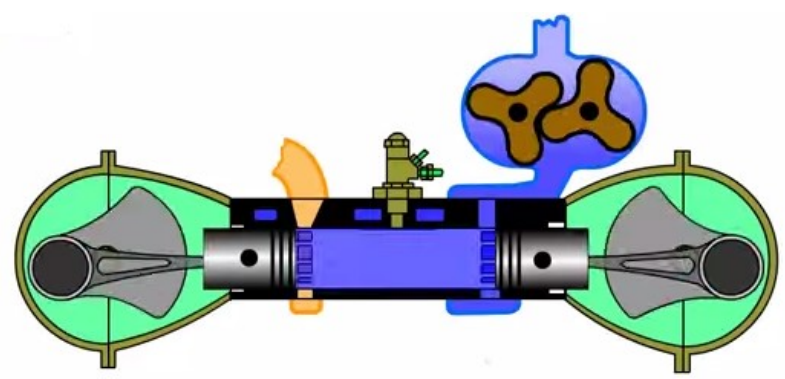

Fig. 1. Opposed piston engine combustion chamber scheme.

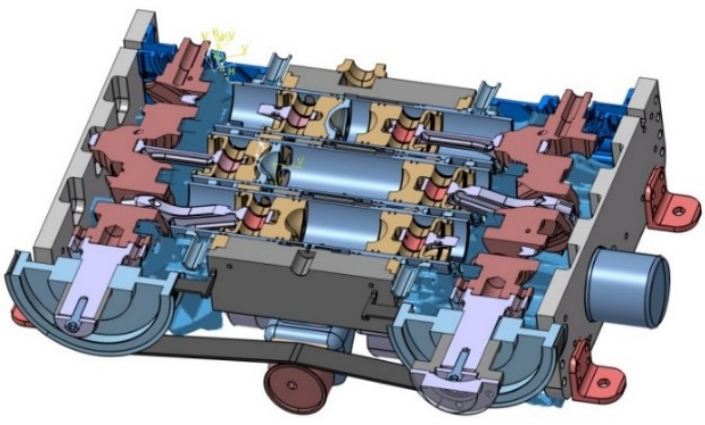

Fig. 2. New construction of the opposed piston engine.
Main advantages of opposed piston engines are: light weight, high power, simple construction and few parts. Main disadvantages are: high thermal load and high mechanical load of crankshaft mechanism. Opposedpiston, two-stroke (OP2S) diesel engines have traditionally provided superior power densities and brake thermal efficiencies, as compared to their four-stroke diesel counterparts but were historically challenged from the standpoint of emissions and durability [9].

In this article two types of the piston from above mentioned engine were analysed. The first piston was made entirely of aluminium. The second piston was a split piston, made of steel and aluminium Simulation studies based on the finite element method (FEM) were performed using Abaqus software.

\section{Model}

The main stages of building a simulation model are presented and described below. The description includes a range from a solid model, through boundary conditions to material data.

\subsection{Piston geometry}

The calculations for two types of the pistons were made. There was assumed, that first piston was made of aluminium alloy (figure 3) and the second was composite piston with aluminium spirt and steel crown (figure 4) [10]. Additionally, the second piston was equipped with cooling channel between skirt and crown [11].

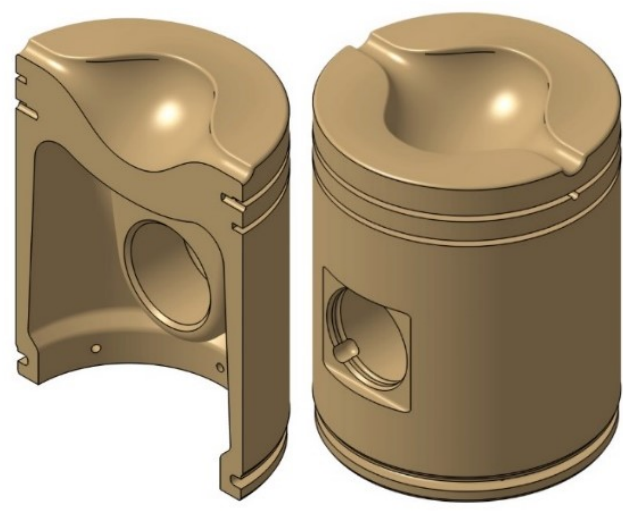

Fig. 3. Aluminium piston model.

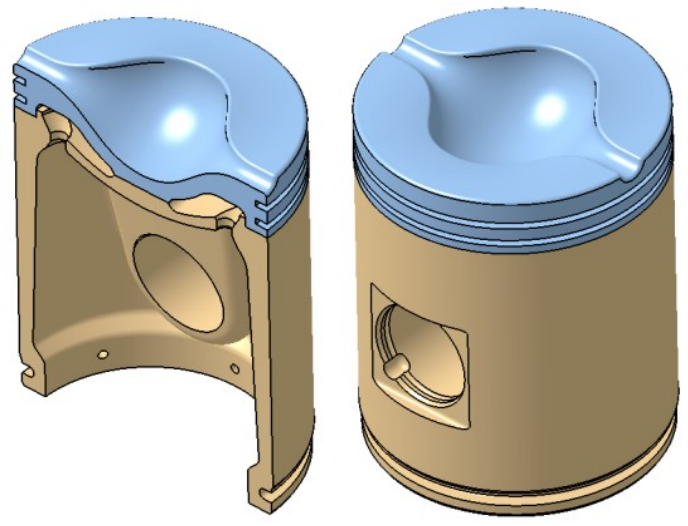

Fig. 4. Composed piston model. 


\subsection{Computational grid}

The simulations were carried out for a computational grid with the size of a single Tetrahedral element of 1 $\mathrm{mm}$. The total number of grid elements was approx. 800,000 (figure 5).

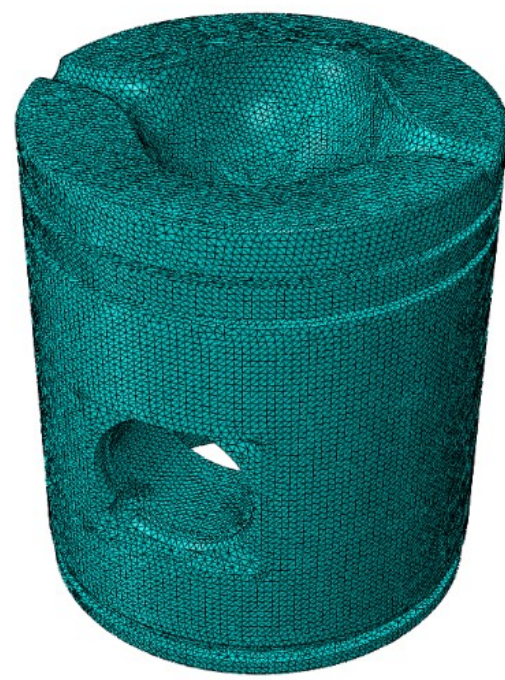

Fig. 5. Computational grid of the piston model.

\subsection{Material data}

The calculations were made as Steady State [7]. Since only the Steady State simulation is analysed, the only necessary material parameter is the Heat transfer coefficient. An aluminium alloy called M174 + was used as the material of the first piston for simulation, and for the second piston, aluminium and steel called $42 \mathrm{CrMn} 04$ were used for the simulation. The material data used during the simulation are presented in Tab. 1. and Tab. 2. Due to the temperature change during the simulation, it was decided to specify the material data with respect to the temperature.

Table 1. Material properties of aluminium alloy called M174 + [12].

\begin{tabular}{|c|c|}
\hline Temperature $\left[{ }^{\circ} \mathbf{C}\right]$ & $\begin{array}{c}\text { Heat transfer coefficient } \\
{[\mathbf{W} / \mathbf{m} \text { K] }}\end{array}$ \\
\hline 20 & 130 \\
\hline 350 & 140 \\
\hline
\end{tabular}

Table 2. Material properties of steel called 42CrMn04 [13].

\begin{tabular}{|c|c|}
\hline Temperature $\left[{ }^{\circ} \mathbf{C}\right]$ & $\begin{array}{c}\text { Heat transfer coefficient } \\
{[\mathbf{W} / \mathbf{m} \text { K] }}\end{array}$ \\
\hline 20 & 33.5 \\
\hline 250 & 34.0 \\
\hline 500 & 34.2 \\
\hline
\end{tabular}

An additional element added in the simulation was the thermal conductivity coefficient occurring at the interface of various materials. It has been introduced by defining the contact properties between the contacting surfaces. These surfaces are shown in figure 6 .

The heat flow conditions between these surfaces were defined by determining the thermal conduction coefficient for the contact of these surfaces and the value of the gap for which heat transfer was impossible (conductivity value for zero gap (contact) and gap value for zero conductivity). These values are presented in Table 3 . In addition, the surfaces were connected via the Tie function, enabling the bonding of calculation grids on the common surface.

Table 3. Heat flow conditions between surfaces.

\begin{tabular}{|c|c|}
\hline $\begin{array}{c}\text { Thermal conductivity } \\
\text { coefficient } \boldsymbol{\lambda}[\mathbf{W} / \mathbf{m} \mathbf{K}]\end{array}$ & $\begin{array}{c}\text { Value of the gap between } \\
\text { surfaces }[\mathbf{m}]\end{array}$ \\
\hline 700 & 0 \\
\hline 0 & 0.001 \\
\hline
\end{tabular}

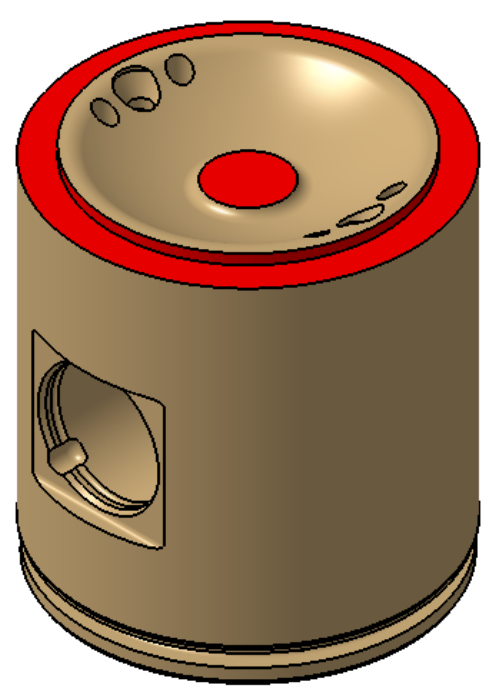

Fig. 6. Contact surfaces of different materials.

\subsection{Boundary conditions}

As boundary conditions, heat transfer coefficient map on the piston crown taken from CFD combustion model and constant piston crown temperature $577^{\circ} \mathrm{C}$, constant temperature $120^{\circ} \mathrm{C}$ on the outer part of the piston skirt and $100^{\circ} \mathrm{C}$ on the inner part were assumed. Heat transfer coefficient $500 \mathrm{~W} / \mathrm{m}^{2} \mathrm{~K}$ on the outer part of the piston skirt and $2500 \mathrm{~W} / \mathrm{m}^{2} \mathrm{~K}$ on the inner part were also assumed $[14,15]$. The test was made for the conditions of take-off power of the engine. Time of engine work in that condition is only $1-2 \%$ time of overall time flight [16], but in this case these were the maximum engine load and maximum temperature.

\subsubsection{Boundary conditions on the piston crown}

To analyse the heat loads on the piston, information on the heat transfer from the combustion simulation is required. Simulation of combustion is carried out assuming a constant surface temperature of the piston (figure 7). Therefore, heat flux is not identical to actual heat flux through the piston. Nevertheless, information on the convective conditions on the piston allows for appropriate modelling of thermal conditions for different piston temperatures, and especially when the piston temperature is the resulting unknown. 


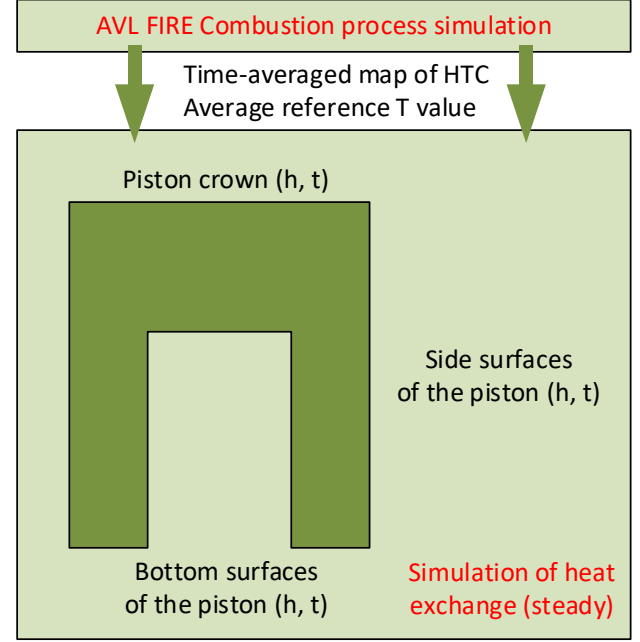

Fig. 7. Diagram of simulation models of piston thermal calculations.

Combustion simulation allows to export averaged convection data using the CFD-FEA COUPLING module. At every fixed time step, the map of $h$ (heat transfer coefficient) and the $T$ value (surface temperature) are collected (figure 8). After the end of the calculation cycle, the thermal map is averaged over time based on the collected data. The basic equation for convective heat transfer was adopted for analysis:

$$
q=h \cdot\left[T_{\text {ref }}-T\right]
$$

where:

$q[W / s]$ - heat flux density,

$h$ - heat transfer coefficient,

$T_{\text {ref }}$ - reference temperature,

$T$ - surface temperature.

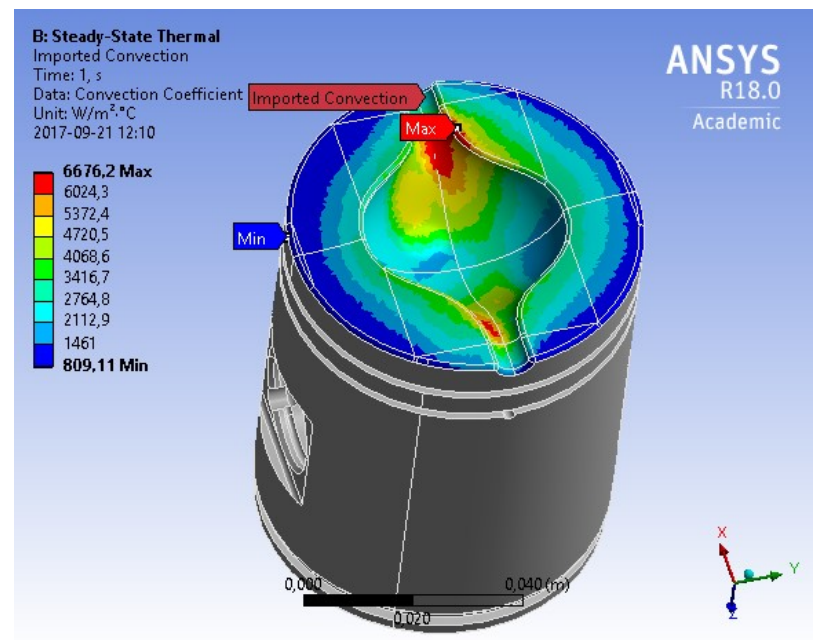

Fig. 8. Map of the heat transfer coefficient on the piston.

\subsubsection{Boundary conditions of outer part of the piston skirt and the inner part}

Thermal conditions acting on the piston were defined for several different surfaces: the outer part of the piston skirt, inner part and piston crown [17]. For each of these surfaces, the conditions for heat removal were determined by determining the temperature of the factor in contact with this surface and the heat transfer coefficient. For the external surface, these values were determined for the oil film medium and cylinder liner and for the internal surface for oil spraying (figure 9).
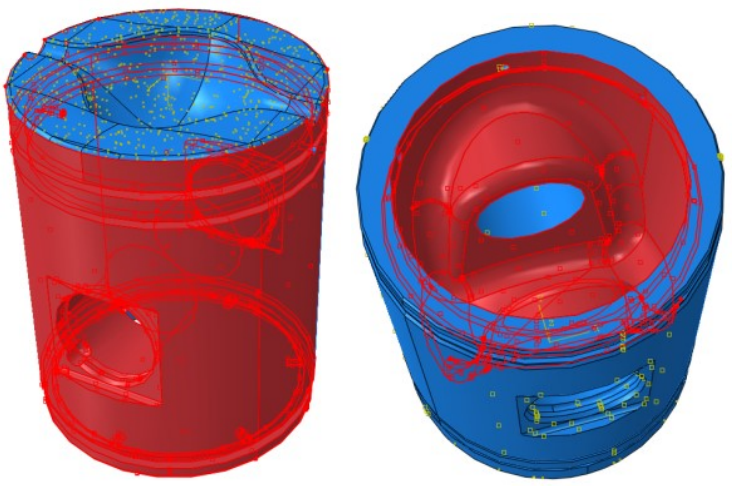

Fig. 9. Boundary conditions for thermal loads of piston - on the left external surface, on the right inner surface.

\section{Results of simulations}

As a result of calculations of thermal loads of the piston, temperature and heat flux maps were presented on the surface and inside of the piston. The temperature was presented in ${ }^{\circ} \mathrm{C}$, while density of heat flux in $\mathrm{W} / \mathrm{m}^{2}$. All results are presented below in figures 10-13. All temperature results have the same legend, which allows to compare them with each other.

Distribution of temperature fields on the piston surface shows that maximum temperatures are located on the sharp edges of the piston bowl, values of maximum temperatures are 402 and $512^{\circ} \mathrm{C}$ for aluminium and composed piston respectively.

Likewise, heat flux looks the same, but the highest value occurs at the side of the injector nozzle. Different temperatures are expected in the spark ignition engines [18].

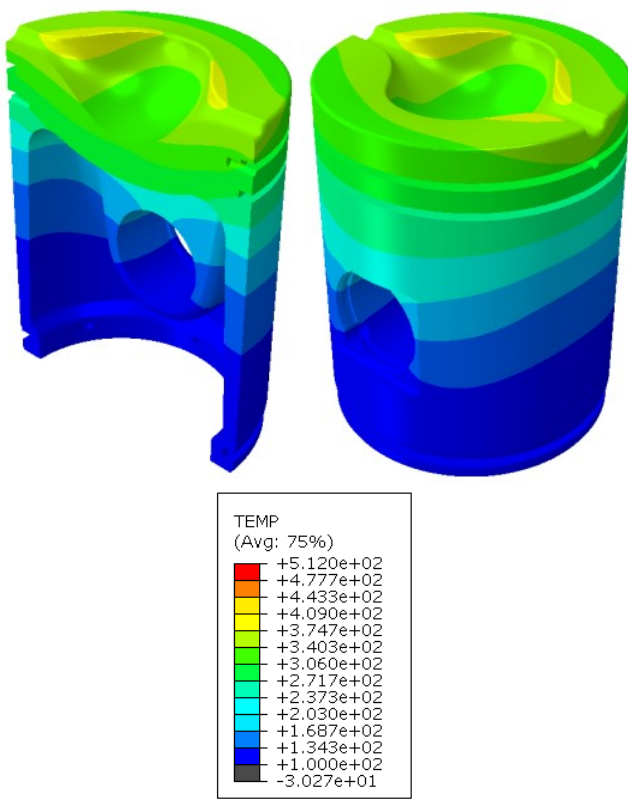

Fig. 10. The distribution of temperature fields for aluminium piston model. 


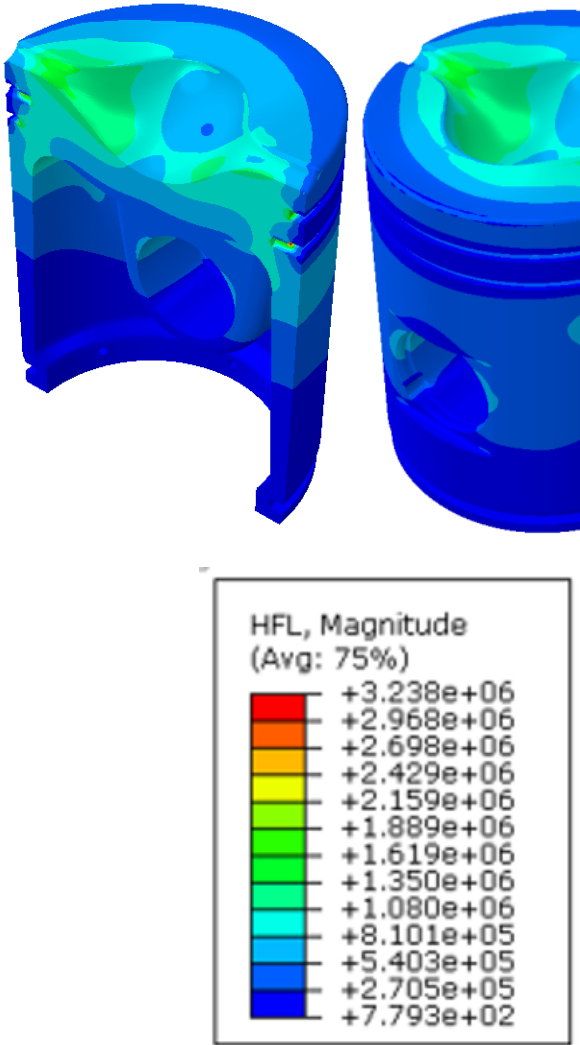

Fig. 11. Distribution of density of heat flux for aluminium piston model.
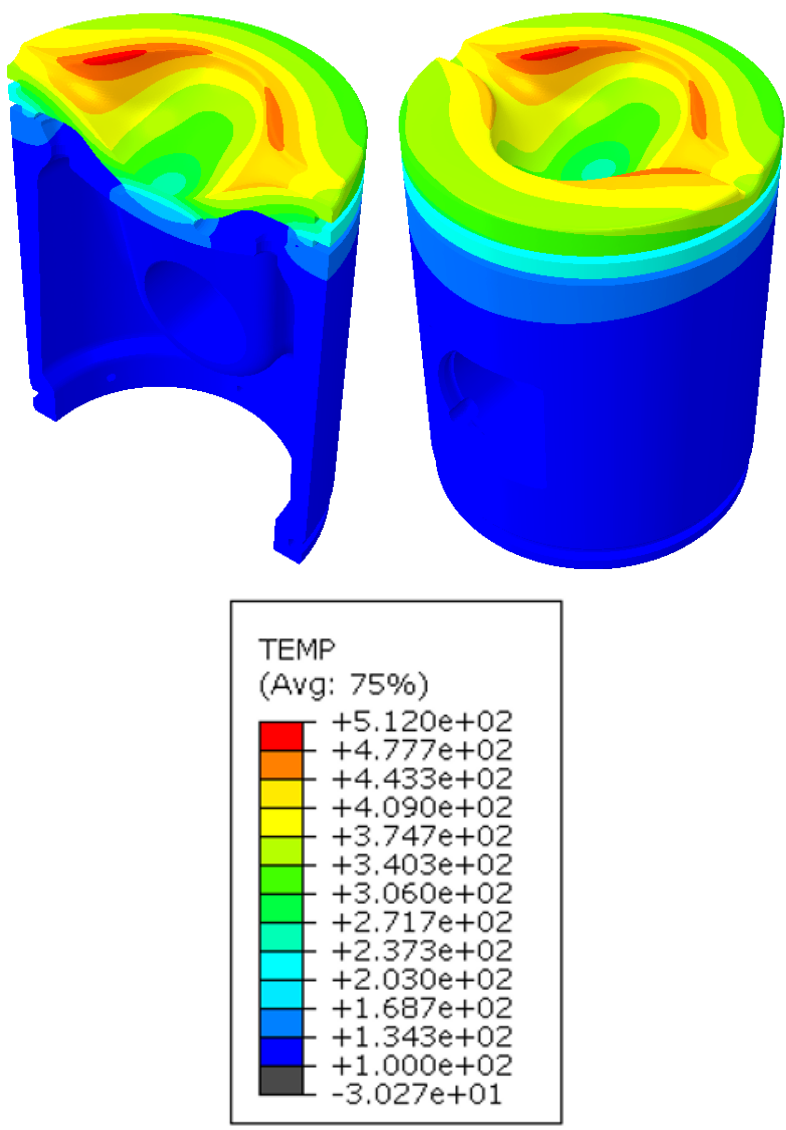

Fig. 12. The distribution of temperature fields for composed piston model.
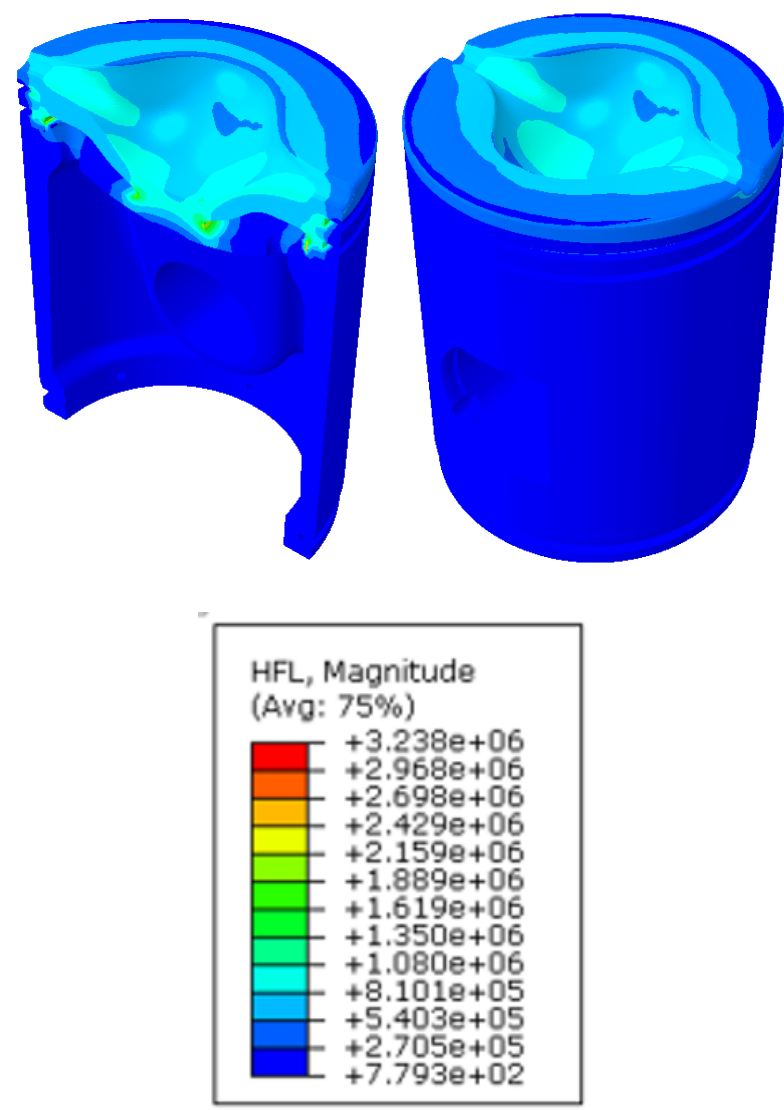

Fig. 13. Distribution of density of heat flux for composed piston model.

\section{Conclusions}

Maximum temperature was observed on the composed piston model $\left(512^{\circ} \mathrm{C}\right)$, but even $402^{\circ} \mathrm{C}$ observed on the first piston is too high value for aluminium alloys. Maximum temperatures were located on the sharp edges of the piston bowl. However, the composite piston with steel crown can withstand the heat load assumed in this project. Additionally, the surfaces of the piston will be coated with titanium oxide to lower the heat transfer coefficient and thus, lower the maximum temperature.

This work has been performed in the cooperation with The Construction Office of WSK "PZL-KALISZ" S.A." and is part of Grant Agreement No. POIR.01.02.00-00-0002/15 financed by the Polish Nation-al Centre for Research and Development.

\section{References}

1. F. Silva, Eng Fail Anal., 13(3):480-92 (2006)

2. L. Gardyński, A. Weroński, In: Proc. 10th international scientific conference

"Communications on the edge of the milleniums, Examination of diesel engine pistons cracking reasons., Silina; (1998)

3. M. D. Röhrle, Pistons for Internal Combustion Engines, Verlag Moderne Industrie, (1995)

4. Aluminium Taschenbuch, 15. Band 3, Auflage, (1997) 
5. M. B. Grieb, H. Christ, B. Plege, Procedia Engineering, Volume 2, Issue 1, Pages 1767-1776, (2010)

6. H. Okamoto, N. Anno, T. Itoh, SAE Technical Paper 920065; (1992)

7. M. Szmytka, F. Salem, A. Rézaï-Aria, International Journal of Fatigue 73, 48-57, (2015)

8. R. Venugopal, N. Abaniand, R .MacKenzie, SAE 2013-01-2423, (2013)

9. M. Flint, J. P. Pirault, SAE International, Warrendale, PA, (2009)

10. A.V. Belogub, N. Van Ziong, O.Yu. Linkov, S.A. Krawczenko, Internal Combustion Engines 1'2016, (2016)

11. R. Venugopal, N. Abani, R. MacKenzie, SAE International, 2013-01-2423, (2013)
12. MAHLE GmbH (Ed.) Pistons and engine testing, 1st Edition (2012)

13. Totalmateria.com

14. H. W. Wu, C. P. Chiu, KSME Journal, Vol. 2, No. 1, 19-27, (1988)

15. The aluminium Automotive Manual, Version 2011 European Aluminium Association

16. Z. Czyz, L. Grabowski, K. Pietrykowski, J. Czarnigowski, M. Porzak, Measurement 113 (2018) 46-52

17. M. Abid, M. Bannikov, J. A. Chattha, 3-D Finite Element Analysis of a diesel engine piston, (2005)

18. M. Wendeker, P. Magryta, A. Majczak, M. Biały, Journal of Kones, 1-18, 683-688 (2011) 